\title{
Aglutininas antileptospiras em caninos do município amazônico de Oriximiná-Pará, Brasil
}

\author{
Serological survey of leptospirosis in dogs of a city located \\ at the Amazonian region in Brazil
}

\author{
Walter Lilenbaum, ${ }^{*}$ Fernanda Rodrigues, ${ }^{\star \star}$ Fabiano Barboza ***
}

\section{Resumo}

O objetivo do presente estudo foi avaliar a ocorrência de evidências sorológicas de leptospirose entre a população canina de centro urbano localizado na região amazônica, com identificação dos sorotipos prevalentes nesta população, e procurar relacioná-los aos usualmente relacionados à fauna silvestre. Foram examinadas pelo método de soroaglutinação microscópica com antígenos vivos (SAM) amostras sanguíneas de 185 caninos de ambos os sexos e idade variável, colhidas randomicamente entre a população do município de Oriximiná, Pará, localizado dentro da região amazônica. Do total de amostras analisadas, $34(18,4 \%)$ mostraram-se reativas, com título mínimo de 1:100. Este valor é bastante próximo ao verificado em outros inquéritos realizados em diversos países. Os sorotipos mais freqüentemente encontrados foram canicola e icterohaemorrhagiae, além de copenhageni, também pertencente ao sorogrupo Icterohaemorrhagiae. Concluiu-se que a proximidade com o ecossistema amazônico e a possibilidade de contato com animais de fauna silvestre não foram determinantes na epidemiologia da leptospirose canina na cidade de Oriximiná, uma vez que estes reproduziram o ciclo epidemiológico urbano tradicionalmente verificado em outras cidades do Brasil e do mundo.

Palavras-chave: leptospirose; caninos; Amazônia.

\begin{abstract}
The purpose of this study conducted in a city of the Amazonian region in Brazil was to evaluate a possible relationship between serotypes usually related to wildlife and those prevalent in the canine population. One hundred eighty five serum samples were tested and a total of 34 positive reactions were observed, corresponding to $18.4 \%$ of the samples. The most prevalent reactions were to icterohaemorrhagiae $(10.3 \%)$, copenhageni $(4.9 \%)$ and canicola $(3.2 \%)$. We verified that the distribution of serotypes in that population is very similar to other urban areas in Brazil and other South American countries. We believe that the proximity of wildlife species did not influence significantly the epidemiology of leptospirosis in this urban canine population.
\end{abstract}

Keywords: leptospirosis; dogs; Amazon.

\section{Introdução}

A leptospirose é umà enfermidade de ocorrência mundial que afeta várias espécies de animais domésticos e silvestres. Roedores e particularmente a ratazana (Rattus norvegicus) representam o mais importante reservatório de leptospiras. No entanto, o cão pode ter grande importância na epidemiologia da doença devido à sua estreita associação com o ambiente e com o homem (Bolin, 1996).

Em determinadas regiões, diferentes sorotipos de leptospiras são prevalentes e estão associados a um ou mais hospedeiros de manutenção, ou reservatórios. Esses reservatórios são freqüentemente representados por espécies silvestres e, em algumas vezes, por animais domésticos. O contato com o reservatório ou com áreas contaminadas com a urina destes animais pode causar infecção em outras espécies (Bolin, 1996).
Após a infecção, os animais tornam-se fonte de disseminação de leptospiras através da urina, e mesmo animais assintomáticos podem eliminar leptospiras. Animais domésticos, como o cão e o gado bovino, assim como espécies silvestres, como ouriços, corças, javalis, raposas, esquilos e mesmo sapos já foram identificados como disseminadores de leptospiras. A eliminação de urina por estes animais contamina o ambiente, particularmente rios e lagos, que se tornam fontes infectantes secundárias, iniciando novas infecções no homem e nos animais (André-Fontaine e Ganière, 1990).

Espécies amplamente distribuídas pelo território brasileiro, como cuícas (Philander opossum), ratos d'água (Nectomys squamipes), gambás (Didelphis albiventris), tatus (Dasypus novemcinctus) e o quati (Nasua nasua), além de marsupiais e primatas da região já foram identificados como portadores

\footnotetext{
* Prof. Adjunto Bacteriologia, Depto. Microbiologia e Parasitologia, UFF - Rua Prof. Hernani Mello, 101, Niterói-RJ, CEP 24210-130, e-mail: mipwalt @vm.uff.br.

** Acadêmico do Curso de Medicina Veterinária da UFF.

*** Acadêmico do Curso de Medicina Veterinária da UFF.
} 
de leptospiras; o que representa um alto potencial de infecção para animais domésticos (Cordeiro et al., 1981; Lins e Lopes, 1984). É amplamente aceito que roedores silvestres desempenhem importante papel na epizootiologia da leptospirose, uma vez que estes animais atuam como disseminadores do agente etiológico. No entanto, existe pouca informação sobre o papel de animais silvestres da Amazônia como reservatórios do patógeno (Lins e Lopes, 1984).

O objetivo do presente estudo foi avaliar a ocorrência de evidências sorológicas de infecção por leptospiras entre a população canina de um centro urbano localizado na região amazônica, e de identificar possíveis relações entre os sorotipos prevalentes na população canina e aqueles usualmente relacionados à fauna silvestre.

\section{Material e métodos}

O experimento foi realizado no Setor de Leptospirose do Departamento de Microbiologia e Parasitologia, no Instituto Biomédico da Universidade Federal Fluminense. Foram examinadas amostras sangüíneas de 185 caninos de ambos os sexos e idade superior a um ano, não vacinados para leptospirose. As amostras foram colhidas randomicamente entre a população do município de Oriximiná, Pará.

O município de Oriximiná localiza-se na área da Amazônia

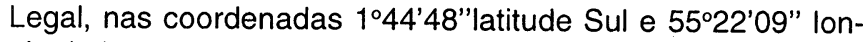
gitude Leste, com altitude de $37 \mathrm{~m}$ acima do nível do mar. Faz fronteira com a Guiana Holandesa e dista $819 \mathrm{~km}$ da capital do estado, Belém. Apresenta clima equatorial superúmido e cerca de $107.000 \mathrm{~km}^{2}$ de área, com população de 50 mil habitantes.

Para o diagnóstico sorológico, utilizou-se o método de soroaglutinação microscópica com antígenos vivos (SAM) e leitura em microscopia de campo escuro, conforme recomendação da Organização Mundial de Saúde (Myers, 1985). Dessa forma, os soros, após centrifugação, foram diluídos a 1/50 em solução de $\mathrm{NaCl}$ a $0,85 \%$ estéril e, com a adição do antígeno, obteve-se a diluição final de $1 / 100$. A reação de aglutinação foi avaliada sob microscopia de campo escuro de acordo com o percentual de leptospiras aglutinadas, variável de (-), em que não se observou aglutinação entre as leptospiras, até ++++ , em que se verificaram mais de $75 \%$ das leptospiras aglutinadas. Considera-se reativa uma amostra em que mais de $50 \%$ das leptospiras se apresentem aglutinadas.

A fim de identificar o mais provável sorotipo infectante, considerou-se a positividade de um soro para o sorotipo em que se observou a aglutinação mais evidente. Como antígenos, foram utilizadas culturas de leptospiras das amostras australis (Ballice), autumnalis (Akiyami A), bratislava (Jez bratislava), castellonis (Castellon 3), bataviae (Van Tienen), canicola (Hond Utrecht IV), hebdomadis (Hebdomadis), icterohaemorrhagiae (RGA), copenhageni (M 20), pomona (Pomona) e wolffi (3705), mantidas em meio de Ellinghausen (conforme Myers, 1985) enriquecido com albumina bovina.

\section{Resultados e discussão}

Do total de amostras analisadas, 34 mostraram-se reativas, com título mínimo de 100 , o que corresponde a $18,4 \%$ dos animais testados, valor bastante próximo ao verificado em outros inquéritos realizados no Brasil (Caldas e Sampaio, 1979; Yasuda et al., 1980). Os sorotipos mais freqüentemente encontrados foram icterohaemorrhagiae $(10,3 \%)$, copenhageni $(4,9 \%)$ e canicola $(3,2 \%)$, conforme Quadro 1. O sorotipo copenhageni, pertencente ao sorogrupo Icterohaemorrhagiae, foi isolado pela primeira vez no Brasil a partir da urina de um cão, em Minas Gerais (Cordeiro e Sulzer, 1983).

Diversos autores brasileiros (Caldas e Sampaio, 1979; Yasuda et al., 1980; Cordeiro e Sulzer, 1983; Souza Netto et al., 1989) têm descrito distribuição similar dos sorotipos de Leptospira interrogans na espécie canina. Também em relatos internacionais os sorotipos mais encontrados em inquéritos sorológicos de caninos são canicola e icterohaemorrhagiae (Bolin, 1996) como também verificado no Peru e no Chile (Ryu, 1976), nas Ilhas Ocidentais de Trinidad (Everard et al., 1979) e na Argentina (Rubel et al., 1997). Embora estes sorotipos sejam os mais freqüentes entre cães de vários países, reações sorológicas para os sorotipos bataviae, andamana, javanica, pyrogenes, cynopeteri e hebdomadis, pomona, grippotyphosa e bratislava já foram verificadas em diversos países (Everard et al., 1979; Souza Netto et al., 1989; Scanziani et al., 1994; Bolin, 1996).

Estes dois sorotipos estão classicamente ligados ao ciclo urbano da leptospirose, uma vez que apresentam como reservatórios principais o roedor Rattus norvegicus e o próprio cão. Sua ocorrência está diretamente ligada a fatores ambientais tais como saneamento básico, indices pluviométricos e coleta regular de lixo, que influenciam no crescimento da população de ratazanas e na ocorrência de contato direto ou indireto do homem ou do cão com a urina contaminada destes reservatórios. A distribuição dos sorotipos verificada na população canina do Município amazônico de Oriximiná reproduziu, portanto, o ciclo epidemiológico urbano tradicionalmente verificado para esta enfermidade. Já os sorotipos mais relacionados aos animais silvestres, como hebdomadis, grippotyphosa e cynopteri na região Amazônica (Lins e Lopes, 1984), além de pomona, australis e mangus, este último pertencente ao sorogrupo Panamá, identificados na região Sudeste do Brasil (Cordeiro et al., 1981) não foram verificados neste inquérito para a população canina do centro urbano de Oriximiná-PA. Assim, acredita-se que a proximidade de animais de fauna silvestre, que poderia estar influenciando a prevalência de leptospirose através do contato direto com a população canina da cidade ou indireto através de águas fluviais, não chega a influenciar significativamente na epidemiologia da leptospirose canina nesta cidade.

Este achado está de acordo com Everard et al: (1979) que, ao analisar a relação da fauna silvestre da llha de Trinidad com a leptospirose canina, considerou que, devido a seus padrões comportamentais, a transmissão entre animais silvestres e cães seria rara em áreas urbanas, embora este fato talvez não fosse confirmado em áreas rurais. Uma população crescente de roedores peridomiciliares e seus ciclos de transmissão envolvendo os sorotipos icterohaemorrhagiae e canicola provavelmente seriam mais comuns entre a população canina urbana da ilha. 
Conclui-se, portanto, que a proximidade com o ecossistema amazônico e a possibilidade de contato com animais de fauna silvestre não foram determinantes na epidemiologia da leptospirose canina na cidade de Oriximiná, uma vez que estes reproduziram o ciclo epidemiológico urbano tradicionalmente verificado em outras cidades do Brasil e do mundo e que não foram evidenciadas reações sorológicas aos sorotipos mais comumente relacionados à fauna silvestre da região Amazônica.

\section{Referências bibliográficas}

ANDRÉ-FONTAINE, G., GANIÈRE, J.P. New Topics on Leptospirosis. Compendium of Immunology, Microbiology and Infectious Diseases, v.13, n.3, p.163-168, 1990.

BOLIN, C.A. Diagnosis of leptospirosis: a reemerging disease of companion animals. Seminars in Veterinary Medicine and Surgery (Small Animals), v.11, n.3, p.166-171, 1996.

CALDAS, E.M., SAMPAIO, M.B. Leptospirose na cidade de Salvador, Bahia, Brasil. International Journal of Zoonosis, v. 6, p. 85-96, 1979.

CORDEIRO, F., SULZER, C.R., RAMOS, A.A. Leptospira interrogans in several wildlife species in southeast Brazil. Pesquisa Veterinaria Brasileira, v.1, p.19-29, 1981.

CORDEIRO, F., SULZER, C. R. Leptospira interrogans serovar copenhageni isolated from a dog in Belo Horizonte, Brazil. Revista Microbiologia, v.14, p. 38-41, 1983.

EVERARD, E., CAZABON, E.P.I., DREESEN, D.W., SULZER, C.R. Leptospirosis in dogs and cats on the island of Trinidad: West Indies. International Journal of Zoonosis v.6, p. 33-40, 1979.
Quadro 1: Perfil de distribuição de aglutininas antileptospiras na população canina de Oriximiná, Pará

\begin{tabular}{|lcccc|}
\hline Sorotipo & No Soros & \% Reativos & \% Total \\
icterohaemorrhagiae & 19 & 55,9 & 10,3 \\
copenhageni & 9 & 26,5 & 4,9 \\
canicola & 6 & 17,6 & 3,2 \\
Subtotal & $\mathbf{3 4}$ & $\mathbf{1 0 0}$ & $\mathbf{1 8 , 4}$ \\
Não-reativas & 151 & - & 81,6 \\
TOTAL & $\mathbf{1 8 5}$ & - & $\mathbf{1 0 0}$ \\
\hline
\end{tabular}

LINS, Z.C., LOPES, M.L. Isolation of Leptospira from wild forest animals in Amazonian Brazil. Transactions of Royal Society of Tropical Medicine and Hygiene, v. 78, p. 124-126, 1984.

MYERS, D. M. Manual de métodos para el diagnóstico de la leptospirose. Centro Panamericano de Zoonoses, Nota Técnica, 30 p., 1985.

RUBEL, D., SEIJO, A., CERNIOGOI, B., VIALE, A, WISNIVESKY-COLLI, C. Leptospira interrogans in a canine population of greater Buenos Aires: variables associated with seropositivity. Pan American Journal of Public Health, v. 2, p. 102-105, 1997.

RYU, E. An international survey of leptospiral aglutinins of dogs by RMAT. International Journal of Zoonosis, v. 3, p. 33-66, 1976.

SCANZIANI, E., CALCATERRA, S., TAGLABUE, S., LUINI, M., GIUSTI, A.M., TOMBA, M. Serological findings in cases of acute leptospirosis in the dog. Journal of Small Animal Practice, v. 35, p. 257-260, 1994.

SOUZA NETTO, B.A., SOUZA, E.T., LILENBAUM, W. Incidence of serovar andamana in canine leptospirosis in Rio de Janeiro, Brazil Ciências Médicas, v: 8, p. 27-30, 1989.

YASUDA, P.H., SANTA ROSA, C.A.,YANAGUITA, R.M. Seasonal variation in the prevalence of leptospirosis in stray dogs in the city of São Paulo, Brazil. Revista Saúde Pública v. 14, p. 589-596, 1980. 